\title{
Problems encountered when administering general anaesthetics in accident and emergency departments
}

\author{
M. R. JAMES \& P. L. MILSOM \\ Departments of Anaesthetics and Accident and Emergency, Pinderfields General Hospital, \\ Wakefield, England
}

\section{SUMMARY}

Junior anaesthetists in 75 English hospitals were surveyed for their views on whether administering general anaesthetics in $A \& E$ departments provoked more anxiety than in the main theatre, and if so what factors contributed to this.

Of these anaesthetists, $71 \%$ were more apprehensive working in A\&E departments than in main theatre; $91 \%$ felt that they were adequately experienced but despite this there was a marked decline in apprehension with increasing experience. Sixty eight per cent of the anaesthetists thought that their assistance was inadequate and only $28 \%$ had an Operating Department Assistant (ODA). Forty eight per cent said that the equipment was inadequate in either standard or maintenance and $40 \%$ said that some of the patients were unsuitable for day case anaesthesia.

The authors recommend that anaesthetists performing general anaesthetics in $A \& E$ departments should be adequately experienced using equipment provided and maintained by the anaesthetic department and assisted by adequately trained nurses or ODAs.

\section{INTRODUCTION}

General anaesthetics are administered in many $A \& E$ departments for minor procedures such as the drainage of abscesses and the manipulation of fractures.

In the authors' experience, although the procedures were minor and the anaesthetics brief, the administration of the anaesthetics often appeared to be difficult and caused the anaesthetist undue anxiety. There appeared to be a number of factors contributing to

Correspondence: Mr M.R. Fames, Registrar in Accident and Emergency, University Hospital, Queen's Medical Centre, Nottingham NG7 2UH, England. 
this: the anaesthetics were often performed by junior anaesthetists, they had different assistants, the equipment in $A \& E$ departments was not the same as that used in main theatre, and the patient was often unclerked, unpremedicated, in pain, and possibly with an incompletely emptied stomach.

This study was set up to see how frequently the administration of $A \& E$ anaesthetics caused anxiety to anaesthetists and, if possible, to identify those factors which contributed to it.

\section{METHOD}

The study looked at those departments which were likely to perform a significant $\stackrel{\frac{D}{3}}{3}$ number of general anaesthetics. Out of a total of $140 \mathrm{~A} \& \mathrm{E}$ departments in England $\stackrel{\omega}{\omega}$ seeing more than 30,000 new patients per year, 75 were randomly selected from the $\vec{G}$ CSA Handbook, 1986.

A letter was sent to the Anaesthetic Chairman in each of these hospitals, asking if he $\stackrel{\circ}{\rightarrow}$ would take part in the study and to distribute the questionnaires to his junior $\vec{s}$ anaesthetic staff.

The questionnaire asked for the experience of the doctor and the number of general anaesthetics he gave per month in the A\&E department. The other questions covered $\stackrel{\oplus}{\square}$ his assistants in the main theatre and the A\&E department, and whether he was mo $\vec{\circ}$ apprehensive administering general anaesthetics in the A\&E department than in the main theatre. If he was more apprehensive he was asked to answer a further question about the adequacy of: his experience, his assistant, the equipment, the patient $\vec{s}$ preparation, or any other reasons. He was given the opportunity to expand any answers.

The questionnaires were completed anonymously but each batch was identifiable from each hospital.

\section{RESULTS}

A high response was achieved; 57 out of the 75 hospitals replied (76\%) with several including letters of comments and interest from the Consultants. One department even sent copies of their own questionnaires which ours had stimulated to be set up, with $₹$ specific relevance to their own department.

Three of the hospitals provided no $A \& E$ anaesthetic service, due to lack of facilities or 7 staff. Three hospitals declined to take part in the survey without giving any reason.

Of the remaining 51 hospitals there were 251 questionnaires returned, 208 of which had been correctly and fully completed.

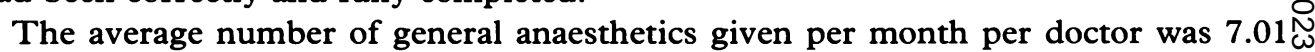
(range 1-40).

In the main theatre $196(94 \%)$ of anaesthetists were assisted by an Operating Department Assistant (ODA), or a dedicated anaesthetic nurse. In the A\&E departments $58(27 \%)$ were assisted by an ODA or dedicated anaesthetic nurse. Of the 
remaining 150 anaesthetists in $A \& E, 134$ were assisted by an $A \& E$ nurse and the remaining 16 had either untrained or no assistance.

One hundred and forty eight of the 208 doctors $(71 \%)$ stated that they were more apprehensive giving general anaesthetics in $A \& E$ than main theatre. These 148 doctors then answered the further question about which factors they thought were adequate or otherwise. Table 1 shows these answers.

Table 1 Factors thought to be adequate in A\&E departments by those anaesthetists who were more apprehensive working there

\begin{tabular}{lrr}
\hline & Yes & No \\
\hline Anaesthetist adequately experienced & $91 \%$ & $9 \%$ \\
Assistance adequate & $32 \%$ & $68 \%$ \\
Equipment adequate & $52 \%$ & $48 \%$ \\
Patient preparation suitable & $60 \%$ & $40 \%$ \\
\hline
\end{tabular}

From Table 1 it can be seen that $68 \%$ of anaesthetists felt that their assistance was inadequate. The type of assistant, however, appears to make a very significant difference; of those anaesthetists who were assisted by an ODA only $9 \%$ felt that their assistance was inadequate, whereas of those who were assisted by someone other than an ODA, $85 \%$ felt that their assistance was inadequate. For the answers to the other questions, there was no significant difference between those general anaesthetics given with and without an ODA.

Figure 1 shows that the percentage of anaesthetists who were more apprehensive in A\&E than main theatre declined steadily with increasing experience. Nevertheless, $52 \%$ of anaesthetists with five or more years experience, still expressed greater apprehension in $\mathrm{A} \& \mathrm{E}$ departments.

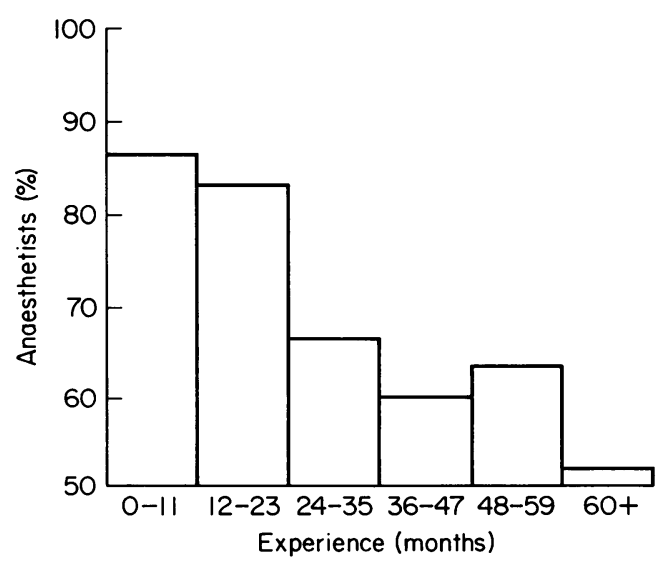

Fig. 1 The percentage of anaesthetists who were more apprehensive giving general anaesthetics in A\&E departments related to their experience. 


\section{DISCUSSION}

It would appear that, in the opinion of the anaesthetists, many general anaesthetics are? carried out on patients who are ill prepared in A\&E departments with unsatisfactory $\underset{\stackrel{0}{\circ}}{\vec{p}}$ equipment and inadequately trained assistants. While it is impossible to quantifyo apprehension and difficult to equate it with risk, the authors feel that it probably indicates a narrower safety margin. Most of the anaesthetics were performed by junior anaesthetists but in their opinion only $9 \%$ felt that they were inadequately experienced. 0 However, the results show a steady decline in apprehension with increasing experience. $\stackrel{\text { Ds }}{~}$ This tends to indicate a lack of insight on the part of junior anaesthetists. It is $\vec{O}$ recommended by the Royal College that anaesthetists should have at least one year of $\vec{\omega}$ experience before performing obstetric anaesthesia. Should a similar recommendation apply to $A \& E$ anaesthetics?

There is a marked difference in anaesthetists' opinions on the adequacy of ODAs andir non-ODAs as assistants. Indeed many of the anaesthetists were highly critical of $A \& E_{\vec{v}}^{\omega}$ nurses who acted as assistants because they were inadequately trained and often had to $\rightarrow$ assist both the anaesthetist and the surgeon. It was recommended in the Report of the Working Party on Assistance for Anaesthetists (1982), that anaesthetists should have $\vec{\infty}$ fully trained assistants wherever general anaesthetics were administered including $A \& E_{\mathbb{O}}^{\mathbb{D}}$ Departments. They defined trained assistance as either an ODA or a nurse who held the $\stackrel{\vec{\oplus}}{\overrightarrow{0}}$ JBCNS. (Trained anaesthetic nurse who has completed the Joint Board of Clinical $\frac{乛}{\Phi}$ Nursing Studies Course 182.) Surely it is unreasonable to expect people to perform tasks for which they are not specifically trained and then criticise them for the way $\mathbb{Z}_{\infty}^{\circ}$

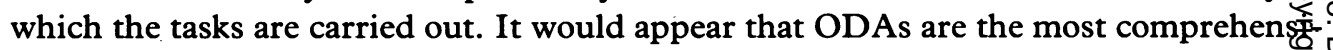
vely trained assistants but are unavailable in many departments. It seems reasonab that nursing staff should be given the opportunity for suitable training, with regular review, as with other extended roles of the nurse.

It was felt that $48 \%$ of departments had inadequate equipment. The commonest $\stackrel{\circ}{\stackrel{\circ}{\circ}}$ criticisms were lack of up-to-date monitoring equipment (e.g. ECG and blood pressure $\vec{\circ}$ monitoring), poor maintenance, and pieces of equipment missing. Is it not the 3 responsibility of the anaesthetic department to equip their anaesthetists and maintain their equipment?

Forty per cent of anaesthetists thought that the patients were unsuitable or ill 3 prepared for day case anaesthesia. Most felt that only patients in the American Society of Anaesthetists (ASA) risk classification groups 1 and 2 should be anaesthetised on a day case basis. The commonest complaints were that patients were selected on surgical and not anaesthetic grounds. Other contributing factors were that patients were incompletely clerked and under investigated, often having undetected intercurrent disease which put them outside the ASA 1 and 2 groupings. Should this not be the responsibility of the $A \& E$ department before contacting the anaesthetist?

These results demonstrate that anaesthetics in A\&E departments do cause the anaesthetist anxiety and the conditions under which general anaesthetics are administered may be far from ideal. There are several possible alternatives to remedy this. One ${ }_{\odot}^{\omega}$ is not to perform general anaesthetics in A\&E departments as was the case in three of the hospitals who replied to the questionnaire. This is not regarded as a viable alternative $\widetilde{\Phi}$ by the authors as it would result in undue delays and cost if the patients were admitted? 
for treatment. If we are to provide a service to the community we must have a general anaesthetic facility available in $\mathrm{A} \& \mathrm{E}$.

In order to assist the anaesthetists with the provision of their service the authors would recommend that:

1. The anaesthetist should be reasonably experienced i.e. not a newly appointed SHO.

2. The equipment is provided and maintained by the anaesthetic department.

3. In order to assist the $A \& E$ staff, the anaesthetic department should provide a suitable pro-forma to be completed for all patients to ensure that a proper anaesthetic assessment is carried out prior to requesting a general anaesthetic.

4. If $A \& E$ nurses are to assist the anaesthetist, they should be given the opportunity of undergoing suitable training under the supervision of the anaesthetic department.

Our results show that many anaesthetists are indeed apprehensive when giving general anaesthetics in A\&E departments, and the reasons for this are multifactorial. The provision of an adequate general anaesthetic service is the joint responsibility of both the Anaesthetic and A\&E departments. Many of these problems could be easily rectified following discussions and co-operation between the two departments in the individual hospitals.

\section{REFERENCE}

Report of Working Party on Assistance for Anaesthetists (1982) Published by Association of Anaesthetists of Great Britain and Ireland. 